\title{
ASSESSMENT OF THE PEDICEL DETACHING AND CRUSHING FORCES OF GRAPE BERRIES TO DETERMINE THE OPTIMAL MECHANICAL HARVESTING TIME
}

\author{
Michele Carrara, Pietro Catania, Felice Pipitone, Mariangela Vallone, Marco Salvia
}

\section{Introduction}

The mechanical harvesting of grapes is an important operation in order to contain the operating costs of the viticultural farms. It's well known that it allows to reduce the costs of the harvest of about $35 \%$ respect to the hand harvesting under the same conditions [5]. One of the limits of the mechanical harvesting of grapes is represented by the production of juice that is mostly due to the energetic action of the shakers that knocks against the grape clusters to allow the detachment of the berries [3]. The production of grape juice is a phenomenon to be limited because it aids the triggering of uncontrolled fermentations that can change the quality of the wine if associated to ambient temperature higher than $30^{\circ} \mathrm{C}[2,6]$. In the vineyards with hedgerow system, the frequency of the shakers is set with regard to the speed of the harvesting machine, to the position of the grape clusters inside the productive area, to the level of the vegetation and to the variety of grapes in order to obtain a high machine efficiency and a low production of grape juice [1]. As a consequence, under the same structural conditions of the plants, the production of grape juice depends on the physical-mechanical characteristics of the berry and particularly on its breaking strength and on its detachment from the pedicel. In fact, a higher breaking strength of the berry directly allows to reduce the production of juice while a lower detachment strength from the pedicel allows to reduce the frequency of the shakers and, then, the production of juice.

In the last years the mechanical harvesting of grapes has also been performed by night because of the lower ambient temperature that reduces the possibility of uncontrolled fermentations, under the same production of grapes juice, and then allows to obtain a

\section{Paper received 27.09.2006; accepted 03.10.2007}

Prof. Ing. Michele CARRara, professore straordinario; Prof. PIEtro Catania, professore associato, Prof. Felice PiPItone, professore ordinario, Ing. Mariangela Vallone, assegnista; Dott. Marco SalVIA, dottorando di ricerca. Dipartimento di Ingegneria e Tecnologie Agro-Forestali, Università degli Studi di Palermo. better product from the qualitative point of view. On the other side, it's well known that the quality of the wine coming from grapes having a high production of juice can be preserved through the timely transfer of the harvested grapes to the cellar even if this isn't always possible because of logistical reasons [4].

From here it comes out the necessity of studying the physical-mechanical characteristics of the berry in order to improve the quality of the mechanically harvested grapes.

In this paper the strength of the berry to the compression force is evaluated through the measurement of the crushing force and the strength of the berry linked to its pedicel measuring its detaching force. The trend of these forces are also analysed with reference to the physical characteristics of the berry (mass and sugar content) during a fixed period before the harvesting.

\section{Materials and methods}

The varieties studied in this paper are Catarratto comune, with white berries, and Nero d'Avola, with black ones. They are very widespread in Sicily because they are included in the regulations for the production of DOC (Controlled Origin Denomination) wines.

The tests were carried out in the period 30th August - 23th September 2005 fixing 5 test times respectively called time 1,2, 3, 4 and 5, performed every 6 days; two representative samples of grape clusters for each variety, both by day and by night, were chosen, respectively called test 1 (by day) and test 2 (by night). The aim was to evaluate the physical-mechanical responses of the grape berry to two different ambient conditions corresponding to the harvesting performed by day and by night. The cluster samples were taken when their own temperature was about $30^{\circ} \mathrm{C}$ by day and $15^{\circ} \mathrm{C}$ by night since the large variability of the ambient temperature both in the day and in the night. The temperature of the clusters was taken into account because, under the same ambient temperature, it can vary both because of some climat- 
ic parameters, such us relative humidity and wind, and because of the position of the clusters into the productive area (height from the ground, covering of the canopy). The temperature of the grape clusters was measured with a portable thermometer (CRISON, TM65 - Spain) provided with a Pt 1000 probe, 200 $\mathrm{mm}$ long. The sampled clusters were put into thermos boxes and quickly took to the laboratory to be analysed. There, thirty berries attached to the pedicel were randomly drown with the scissors from the grape clusters in order to measure the following physical-mechanical parameters: crushing force, pedicel detaching force and mass of the berry.

The crushing force is the compression force that is necessary to apply to the integral and provided with the pedicel berry in order to cause the first grape juice coming out; this allows to evaluate the breaking strength of the berry because the breaking itself causes the production of juice during the mechanical harvesting. The detaching force is the traction force that is necessary to apply to the berry to cause its detachment from the pedicel; this allows to evaluate the strength of the berry-pedicel system from the mechanical harvesting point of view.

These indexes, compared to the sugar content, that is the main qualitative parameter of the grapes [7], allow to identify the right period for the mechanical harvesting in order to obtain wines of quality from mechanically harvested grapes.

The crushing and detaching tests were performed through an electronic dynamometer (IMADA, DPS 5R - USA) linked to an electronic stand (figure 1). The data were downloaded to a personal computer where a software recorded the trend of the applied forces and read the peaks corresponding to the crushing and detaching forces. The crushing of the berries was made by a steel plate having area of $50.24 \mathrm{~mm}^{2}$. The detachment of the berries from the pedicel was realised through a clamp linked in the first side to the dynamometer and in the other one to the pedicel. The sliding speed of the dynamometer on the stand was $0.83 \mathrm{~mm} / \mathrm{s}$. The crushing and detaching tests were performed on 15 berries each, while the sugar content and the mass were recorded for all the 30 berries. The sugar content was recorded through a portable optic

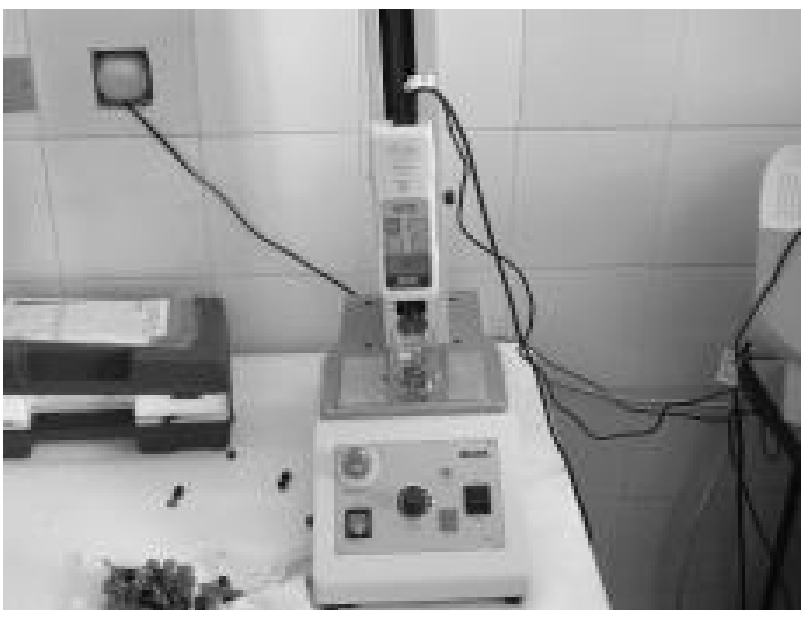

Fig. 1 - IMADA dynamometer during the tests.

refractometer (Milwaukee, MR100ATC - USA) while the weight of the berries was measured with an electronic balance (ORMA, BC4000S - Italy).

The data were statistically analysed and the mean compared with Duncan's multiple comparison procedure $(\mathrm{p}=0.05)$.

\section{Results and discussion}

In figure 2 the trend of the detaching and crushing forces of test 1 for the variety Catarratto comune is represented. It shows the crushing force having a decreasing linear trend $\left(\mathrm{R}^{2}=0.95, \mathrm{p}=0.0041\right)$ going from $9.49 \mathrm{~N}$ in the first time to $6.48 \mathrm{~N}$ in the last one; the decrease is $32 \%$ in the whole period and $15 \%$ between the last two times. It results that the variability of the breaking strength of the berry in the whole period will cause a different production of juice, under the same conditions. Duncan's multiple comparison procedure showed the presence of statistical significant differences between the times 1-4, 1-5, 2-5 and 3-5 (table 1). The difference between time 3 and time 5 can induce to plan the harvesting near to time 3 , when the breaking strength would be higher for this variety. The pedicel detaching force shows a linear decreasing trend $\left(\mathrm{R}^{2}=0.95, \mathrm{p}=0.0045\right)$ going from $1.71 \mathrm{~N}$ in time 1 to $1.41 \mathrm{~N}$ in the last one; it

\begin{tabular}{|c|c|c|c|c|c|c|c|c|c|c|c|c|}
\hline \multirow{3}{*}{ Time } & \multicolumn{4}{|c|}{ Mean between test 1 and test 2} & \multicolumn{4}{|c|}{ Test 1} & \multicolumn{4}{|c|}{ Test 2} \\
\hline & \multicolumn{2}{|c|}{$\begin{array}{c}\text { Mass } \\
{[\mathrm{g}]}\end{array}$} & \multicolumn{2}{|c|}{$\begin{array}{c}\text { Sugar content } \\
{[\mathrm{g} / \mathrm{l}]} \\
\end{array}$} & \multicolumn{2}{|c|}{$\begin{array}{c}\text { Detaching force } \\
{[\mathrm{N}]}\end{array}$} & \multicolumn{2}{|c|}{$\begin{array}{c}\text { Crushing force } \\
{[\mathrm{N}]}\end{array}$} & \multicolumn{2}{|c|}{$\begin{array}{c}\text { Detaching force } \\
{[\mathrm{N}]}\end{array}$} & \multicolumn{2}{|c|}{$\begin{array}{c}\text { Crushing force } \\
{[\mathrm{N}]}\end{array}$} \\
\hline & mean & st.dev. & mean & st.dev. & mean & st.dev. & mean & st.dev. & mean & st.dev. & mean & st.dev. \\
\hline 1 & $1.71 \mathrm{~b}$ & 0.18 & $186.9 \mathrm{~b}$ & 1.48 & 1.71 n.s. & 0.43 & $9.49 \mathrm{a}$ & 2.11 & 2.17 n.s. & 0.59 & $9.37 \mathrm{a}$ & 2.43 \\
\hline 2 & $1.82 \mathrm{~b}$ & 0.48 & $190.3 \mathrm{ab}$ & 0.71 & 1.68 n.s. & 0.46 & $8.39 \mathrm{ab}$ & 1.54 & 2.08 n.s. & 0.47 & $7.90 \mathrm{ab}$ & 1.88 \\
\hline 3 & $2.04 \mathrm{a}$ & 0.33 & $198.2 \mathrm{ab}$ & 4.01 & 1.62 n.s. & 0.61 & $8.15 \mathrm{ac}$ & 2.07 & 1.89 n.s. & 0.57 & $7.11 \mathrm{~b}$ & 2.25 \\
\hline 4 & $2.10 \mathrm{a}$ & 0.21 & $202.5 \mathrm{ab}$ & 1.51 & 1.52 n.s. & 0.50 & $7.59 \mathrm{bcd}$ & 1.40 & 1.87 n.s. & 0.53 & $7.05 \mathrm{~b}$ & 1.86 \\
\hline 5 & $2.15 \mathrm{a}$ & 0.26 & $206.2 \mathrm{a}$ & 0.91 & 1.41 n.s. & 0.56 & $6.48 \mathrm{~d}$ & 0.69 & 1.85 n.s. & 0.50 & $5.45 \mathrm{c}$ & 1.83 \\
\hline
\end{tabular}

Note: Different letters in the column denote a statistically significant difference at the $95.0 \%$ confidence level.

TABLE 1 - Results of Duncan's multiple comparison procedure among the means for the variety Catarratto comune. 


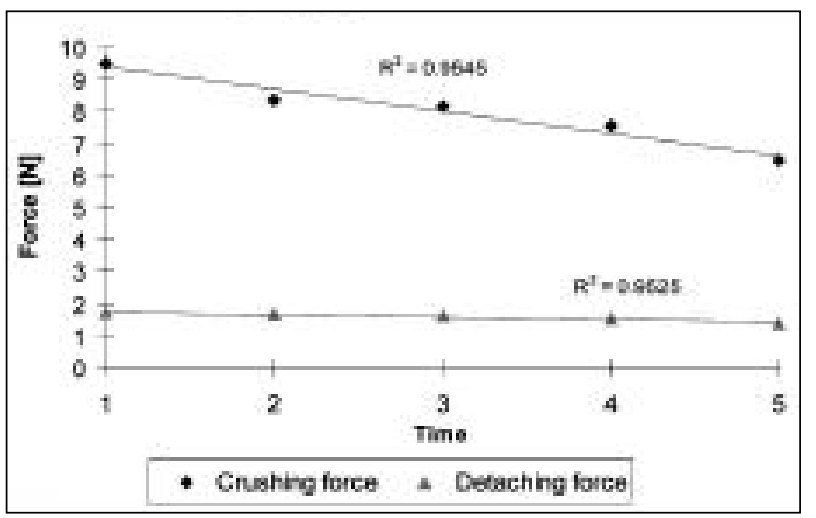

Fig. 2 - Trend of the detaching and crushing forces of test 1 for the variety Catarratto comune.

decreases of $18 \%$ in the whole period and about $8 \%$ between the last two times. It points out that the decreasing of the detaching force for the variety Catarratto comune is lower (about 50\%) than the decrease of the crushing force in the whole period. The statistical analysis for the detaching force doesn't show any significant differences between the considered times; it comes out that the detaching force of the berry doesn't particularly influence the choice of the optimal mechanical harvesting time in order to limit the production of grape juice.

In figure 3 the mean values between test 1 and test 2 of the mass and the sugar content of the berries of the variety Catarratto comune are represented; both the mass and the sugar content show an increasing linear trend with $\mathrm{R}^{2}$ respectively $0.92(\mathrm{p}=0.0074)$ and $0.98(\mathrm{p}=0.0011)$. In particular, the mass of the berry has a total increase of $20 \%$ and a null increase between the last two times and statistically significant differences between times 1-3, 1-4, 1-5, 2-3, 2-4 and 2-5 (table 1). The sugar content shows an increase of about $10 \%$ going from $186.9 \mathrm{~g} / 1$ to $206.2 \mathrm{~g} / 1$, and a $2 \%$ increase between the last two times with statistically significant differences between times 1 and 5 (table 1). Then, it comes out that the sugar content and the mass values obtained in the last two times don't justify the delay in the mechanical harvesting since in time 4 and 5 the strenght of the berry is lower than the previous times.

In figure 4 the trend of the detaching and crushing forces of test 2 for the variety Catarratto comune is represented. It shows the crushing force having a decreasing linear trend $\left(\mathrm{R}^{2}=0.92, \mathrm{p}=0.0084\right)$ going from $9.37 \mathrm{~N}$ in the first time to $5.45 \mathrm{~N}$ in the last one; the decrease in the whole period is $42 \%$ while the decrease between the last two times is $23 \%$.

The results show statistically significant differences in the crushing forces by night between the times $1-3,1-4,1-5,2-5,3-5$ and $4-5$ (table 1 ), so by night the variability of the breaking strength of the berry is larger than by day. As a consequence, the optimal mechanical harvesting time by night would be advanced with regard to the daytime harvesting.

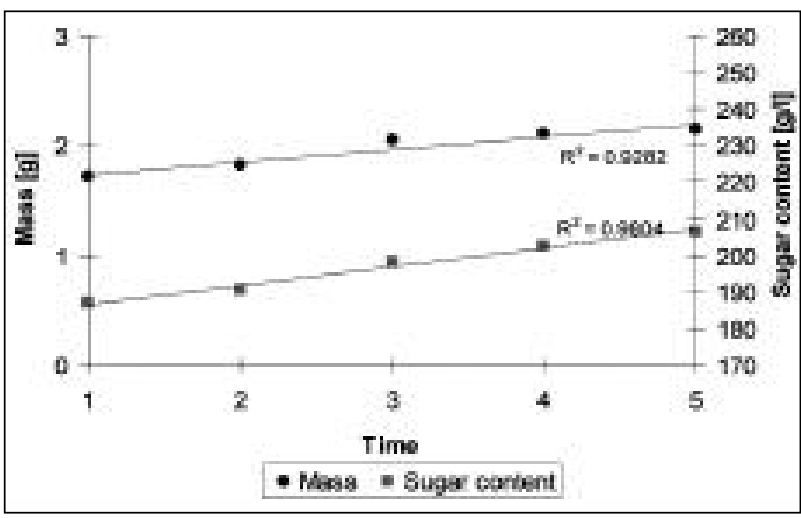

Fig. 3 - Trend of the mass and sugar content for the variety Catarratto comune.

The detaching force shows a decreasing linear trend $\left(\mathrm{R}^{2}=0.87, \mathrm{p}=0.0203\right)$. The values of the first and the last times are respectively $2.17 \mathrm{~N}$ and $1.85 \mathrm{~N}$, so the detaching force has a $18 \%$ decrease in the whole period and a $8 \%$ decrease between the last two times. There are no statistically significant differences between the different times.

From the comparison between test 1 and 2 for the variety Catarratto comune it comes out that the crushing forces do not differ from the statistical point of view; as a consequence, the day and the night do not influence, under the same conditions, the breaking strength of the berry and then the production of grape juice coming from the use of the harvesting machine. On the contrary, the detaching forces show statistically significant differences in the times 1,2 and 5, so the detaching force by night is higher in the first two and in the last time; these are the worst times to harvest because it's necessary to increase the frequency of the shakers to detach the berry consequently causing a higher production of grape juice.

Figure 5 represents the trend of the detaching and crushing forces of test 1 for the variety Nero d'Avola. The crushing force shows a decreasing linear trend $\left(\mathrm{R}^{2}=0.85, \mathrm{p}=0.0257\right)$ going from $8.89 \mathrm{~N}$ in time 1 to $4.80 \mathrm{~N}$ in time 5 ; the decrease is about $46 \%$ in all

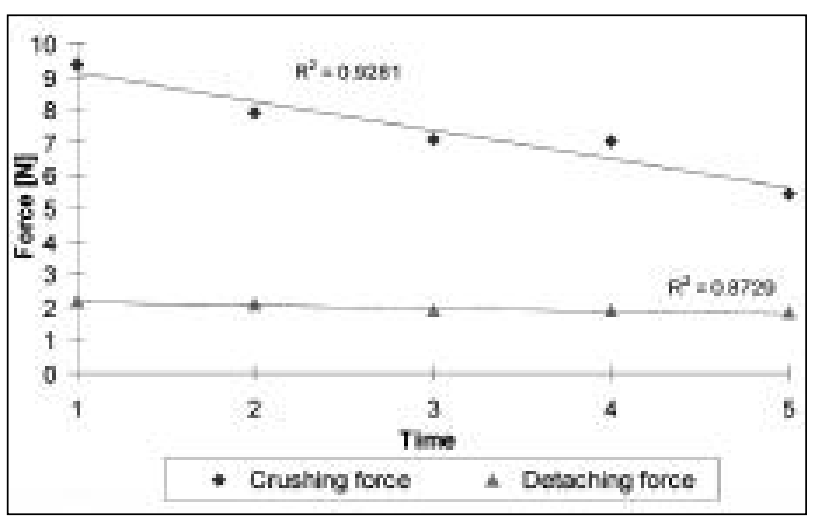

Fig. 4 - Trend of the detaching and crushing forces of test 2 for the variety Catarratto comune. 


\begin{tabular}{|c|c|c|c|c|c|c|c|c|c|c|c|c|}
\hline \multirow[b]{2}{*}{ Time } & \multicolumn{4}{|c|}{ Mean between test 1 and test 2} & \multicolumn{4}{|c|}{ TEST 1} & \multicolumn{4}{|c|}{ TEST 2} \\
\hline & \multicolumn{2}{|c|}{$\begin{array}{c}\text { Mass } \\
{[\mathrm{g}]} \\
\end{array}$} & \multicolumn{2}{|c|}{$\begin{array}{c}\text { Sugar content } \\
{[\mathrm{g} / \mathrm{l}]}\end{array}$} & \multicolumn{2}{|c|}{$\begin{array}{l}\text { Detaching force } \\
{[\mathrm{N}]}\end{array}$} & \multicolumn{2}{|c|}{$\begin{array}{c}\text { Crushing force } \\
{[\mathrm{N}]}\end{array}$} & \multicolumn{2}{|c|}{$\begin{array}{l}\text { Detaching force } \\
\qquad[\mathrm{N}]\end{array}$} & \multicolumn{2}{|c|}{$\begin{array}{c}\text { Crushing force } \\
{[\mathrm{N}]}\end{array}$} \\
\hline & mean & st.dev. & mean & st.dev. & mean & st.dev. & mean & st.dev. & mean & st.dev. & mean & st.dev. \\
\hline 1 & $1.64 \mathrm{~b}$ & 0.19 & $200.8 \mathrm{c}$ & 1.32 & $2.26 \mathrm{a}$ & 0.57 & $8.89 \mathrm{a}$ & 2.22 & $2.11 \mathrm{a}$ & 0.44 & $8.29 \mathrm{a}$ & 1.76 \\
\hline 2 & $1.72 \mathrm{~b}$ & 0.42 & $224.8 \mathrm{~b}$ & 0.59 & $2.20 \mathrm{ab}$ & 0.43 & $7.79 \mathrm{a}$ & 1.03 & $2.01 \mathrm{ab}$ & 0.59 & $7.41 \mathrm{a}$ & 0.80 \\
\hline 3 & $2.04 \mathrm{a}$ & 0.32 & $246.2 \mathrm{a}$ & 0.53 & $2.15 \mathrm{ab}$ & 0.38 & $5.17 \mathrm{~b}$ & 1.26 & $1.71 \mathrm{bc}$ & 0.48 & $5.13 \mathrm{~b}$ & 1.22 \\
\hline 4 & $2.15 \mathrm{a}$ & 0.36 & $250.0 \mathrm{a}$ & 0.49 & $1.99 \mathrm{ab}$ & 0.62 & $4.95 \mathrm{~b}$ & 1.03 & $1.68 \mathrm{bc}$ & 0.42 & $4.90 \mathrm{~b}$ & 1.38 \\
\hline 5 & $2.25 \mathrm{a}$ & 0.45 & $252.9 \mathrm{a}$ & 0.68 & $1.72 \mathrm{~b}$ & 0.74 & $4.80 \mathrm{~b}$ & 1.35 & $1.63 \mathrm{bc}$ & 0.38 & $4.58 \mathrm{~b}$ & 1.68 \\
\hline
\end{tabular}

Note: Different letters in the column denote a statistically significant difference at the $95.0 \%$ confidence level.

TABLE $\quad 2$ - Results of Duncan's multiple comparison procedure among the means for the variety Nero d'Avola.

the period and only $3 \%$ between the last two times so that the variability of the breaking strength of the berry in the whole period will induce a different production of juice, under the same conditions. Duncan's multiple comparison procedure showed the presence of statistical significant differences between the times $1-3,1-4,1-5,2-3,2-4$ and 2-5 (table 2). This result justifies the delay in the mechanical harvesting for this variety of grapes, showing the breaking strength of the berry a low variability in the last times.

The pedicel detaching force shows a linear decreasing trend $\left(\mathrm{R}^{2}=0.89, \mathrm{p}=0.0173\right)$ going from $2.26 \mathrm{~N}$ in the first time to $1.72 \mathrm{~N}$ in the last one; it decreases of $24 \%$ in the whole period and about $14 \%$ between the last two times. Comparing the values of the crushing and detaching forces for the variety Nero d'Avola in the whole period, it comes out that the crushing force highly decreases than the detaching one.

The statistical analysis for the detaching force gave statistically significant differences between times 1 and 5; even for this variety of grapes the detaching force of the berry from the pedicel doesn't particularly influence the choice of the optimal mechanical harvesting time in order to limit the production of grape juice.

Figure 6 represents the mean values between test 1 and test 2 of the mass and the sugar content of the berries of the variety Nero d'Avola; both the mass and

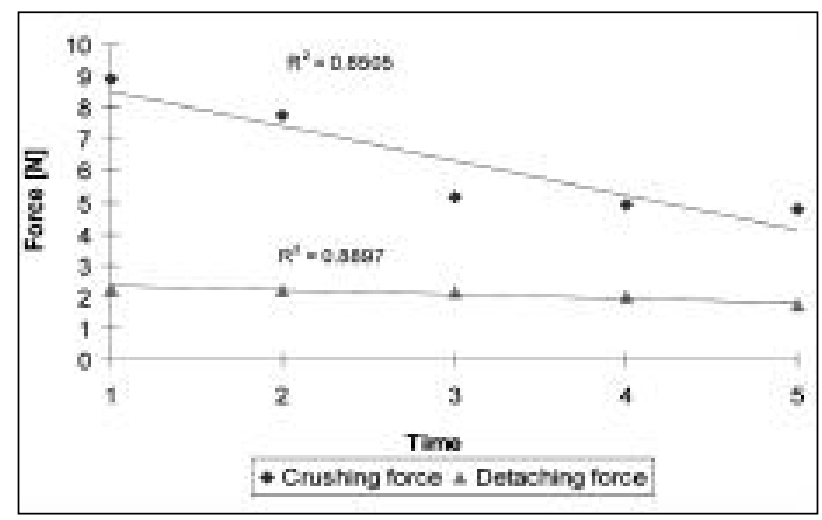

Fig. 5 - Trend of the detaching and crushing forces of test 1 for the variety Nero d'Avola. the sugar content show an increasing linear trend having $\mathrm{R}^{2}$ respectively $0.95(\mathrm{p}=0.0048)$ and $0.86(\mathrm{p}=$ 0.0230 ). In particular, the mass of the berry has a $27 \%$ total increase and a 5\% increase between the last two times and statistically significant differences between times 1-3, 1-4, 1-5, 2-3, 2-4 and 2-5 (table 2). The sugar content shows an increase of about $26 \%$ going from $200.8 \mathrm{~g} / 1$ to $252.9 \mathrm{~g} / 1$ and an almost null increase between the last two times with statistically significant differences between times 1-2, 1-3, 1-4, 1-5, 2-3, 2-4 and 2-5 (table 2). The low variability of the values of sugar content and mass of the berry in the last times for this variety, allows to plan the time of the harvesting inside a large period going from time 3 to time 5 .

In figure 7 the trend of the detaching and crushing forces of test 2 for the variety Nero d'Avola is represented. It shows the crushing force having a decreasing linear trend $\left(\mathrm{R}^{2}=0.88, \mathrm{p}=0.0182\right)$ going from $8.29 \mathrm{~N}$ in the first time to $4.58 \mathrm{~N}$ in the last one; the decrease in the whole period is about $45 \%$ while the decrease between the last two times is $7 \%$. The results of the statistical analysis show statistically significant differences between the times 1-3, 1-4, 1-5, 2-3, 2-4 and 2-5 (table 2). The detaching force shows a decreasing linear trend $\left(\mathrm{R}^{2}=0.89, \mathrm{p}=0.0168\right)$; the values of the first and the last times are respectively 2.11 $\mathrm{N}$ and $1.63 \mathrm{~N}$ so the detaching force has a $33 \%$ decrease in the whole period and only a $3 \%$ decrease be-

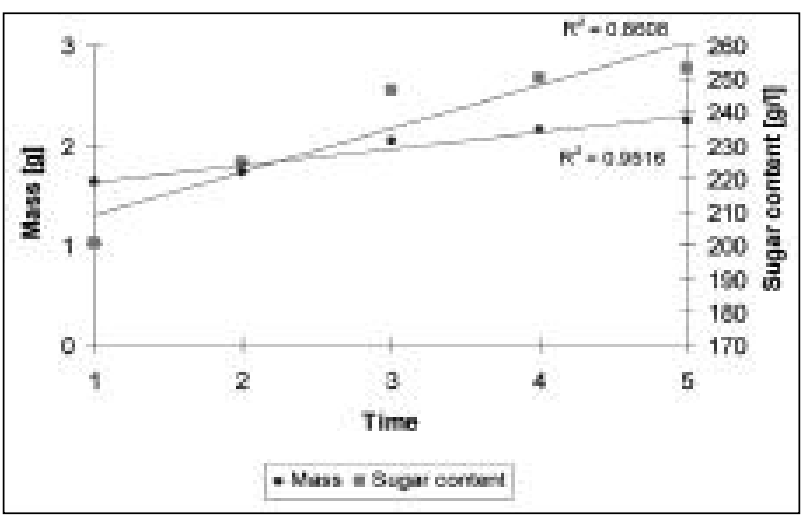

Fig. 6 - Trend of the mass and sugar content for the variety Nero d'Avola. 


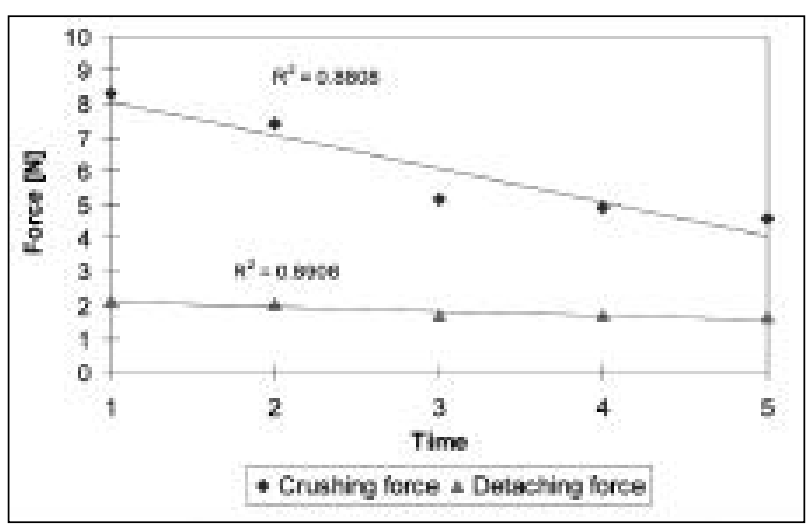

Fig. 7 - Trend of the detaching and crushing forces of test 2 for the variety Nero d'Avola.

tween the last two times. The statistical analysis results show the presence of statistically significant differences between times 1-3, 1-4 and 1-5.

From the comparison between tests 1 and 2 for the variety Nero d'Avola it comes out that the crushing forces do not differ from the statistical point of view while the detaching forces show statistically significant differences in time 3 .

\section{Conclusions}

Studying the physical-mechanical characteristics of the grape berry, the research allowed to verify that the optimal mechanical harvesting time in order to obtain wines of quality can not correspond to the optimal hand harvesting time. In fact, in the hand harvesting the parameter mainly taken into account in order to plan the harvesting of grapes, is the sugar content. The research showed that it's essential to evaluate the breaking strength of the berry and its pedicel detachment resistance in order to improve the quality of wine coming from mechanically harvested grapes. Their correlation with the sugar content allows to find out the optimal mechanical harvesting time in order to obtain a low production of grape juice and, then, wines of quality from mechanically harvested grapes.

The results represent the bases for further investigations aimed to get better the mechanical characteristics of the berry in order to improve the efficiency of a very important operation such as the mechanical harvesting of grapes.

\section{References}

[1] Clary C.D., Steinhauer R.E., Frisinger J.E., PefFer T.E., Evaluation of machine-vs. hand-harvested
Chardonnay, American Journal of Enology and Viticulture, (1990), 41, 176-181.

[2] Febo P., Peri G., PiPItone F., Un Impianto per inibire il processo di ossidazione durante la raccolta meccanica delle uve bianche, Atti del VI Convegno Nazionale di Ingegneria Agraria (1997), Ancona 1112 settembre 3, 509-513.

[3] MoRrIs J.R., Factors influencing grape juice quality, HortTechnology, (1998), 8, 471-478.

[4] Ough C.S., BERG H.W., Simulated mechanical harvest and gondola-transport. Effect of temperature, atmosphere, and skin-contact on chemical and sensory qualities of white wines, American Journal of Enology and Viticulture, (1971), 22, 194-198.

[5] Pipitone F., Peri G., Catania P., Calafatello A.R., VAllone M., Effetti della lunghezza dei filari sulla capacità operativa delle vendemmiatrici, L'Informatore Agrario, (2003), 2, 55-58.

[6] POCOCK K.F., WATERS E.J. The effect of mechanical harvesting and transport of grapes, and juice oxidation, on the protein stability of wines, Australian Journal of Grape and Wine Research (1998), 4, 136-139.

[7] Zardini F., De Biasi C., Falcetti M., CAmpostrini F., Scelta dell'epoca vendemmiale, L'Informatore Agrario, (2004), 30, 39-48.

\section{SUMMARY}

The mechanical harvesting of grapes is an important operation in order to contain the operating costs of the viticultural farms. One of the limits of the mechanical harvesting of grapes is represented by the production of juice that is mostly due to the energetic action of the shakers that knocks against the grape clusters to allow the detachment of the berries. As a consequence, under the same structural conditions of the plants, the production of grape juice depends on the physical-mechanical characteristics of the berry and particularly on its breaking strength and on its detachment from the pedicel.

In this paper the strength of the berry to the compression force is evaluated through the measurement of the crushing force and the strength of the berry linked to its pedicel measuring its detaching force. The study was performed on two variety of grapes very widespread in Sicily: Catarratto comune and Nero d'Avola.

The research showed that the evaluation of the breaking strength of the berry and its pedicel detachment resistance, correlated with the sugar content, allows to find out the optimal mechanical harvesting time in order to obtain a low production of grape juice and, then, wines of quality from mechanically harvested grapes.

Key words: Grape berries, grape juice, mechanical harvesting, detaching force, crushing force. 
Riv. di Ing. Agr. (2006), 4, 36.

The ordinates of both figures $1 \mathrm{~B}$ and $1 \mathrm{D}$ please read $V_{\mathrm{s}}=\rho_{\mathrm{b}}{ }^{-1}$ instead of $V_{\mathrm{s}}=\rho_{\text {sol }}{ }^{-1}$ 